\title{
RESHAPING TEACHING STRATEGIES FOR INNOVATIVE MATERIALS IN ART AND DESIGN
}

\author{
Elif Ozden-Yenigun ${ }^{1}$ \\ ${ }^{1}$ Royal College of Art, School of Design, Textiles, (United Kingdom)
}

\begin{abstract}
Textiles have faced a new challenge with the advancement of electronics and nanotechnology. Smart textiles represented the newest stage of the technological revolution, which is grounded in new fibre materials and textile manufacturing processes for fabrics exhibiting additional functionalities. These fabrics have been engineered to see, hear, sense, communicate, store and convert energy, and even tune colour. This multi-disciplinary field includes end-to-end prototyping from fibre design to system integration of new textile based products, and also requires to comprehend the underpinnings of material science and nanotechnology. Classical teaching methods are not effective enough to engage and motivate students with art and design background. The real question is, "How do you teach smart textiles in graduate level, especially to the students who never studied quantum mechanics, differential equations and fluid dynamics before?" This study outlines reshaping teaching strategies for innovative and tangible materials in art and design education, and addresses the importance of student-led experiences in research projects and integration of hands-on learning.
\end{abstract}

Keywords: hands-on learning, research, higher education, active learning

\section{INTRODUCTION}

Smart textiles have benefited greatly from the mature field of textile science, the emerging field of nanotechnology and new scientific innovations while exploring the interface between craft and technology. These intelligent fabrics can be hardly explained from a mono disciplinary perspective. Even though, engineering design and industrial design have been considered opposite due to using different design practices [1,2]. The key to success is relying on merging collaborative design processes created by the contribution of textile making and engineering design. Kim and Lee discussed the role of engineers and designers, both in outside-in and inside- out design approaches, and recommended to adopt these approaches to launch functioning, reliable and appealing products to the market [3]. There have been several attempts to reveal effective design processes from an integrative perspective $[3,4]$. However, little is known from education point how educators can shape these minds throughout the years spent in higher education to create a common language for an effective collaboration.

If we take a look the US Accreditation Board for Engineering and Technology's (ABET) definition for "engineering", it is defined as "The creative application of scientific principles to design or develop structures, machines, apparatus, or manufacturing processes, or works utilizing them singly or in combination; or to construct or operate the same with full cognizance of their design; or to forecast their behaviour under specific operating conditions; all as respects an intended function, economics of operation and safety to life and property" [5]. In other words, engineers are creators of our physical functioning world, who must follow universal standards and codes of appropriate ethical behaviour [6]. In spite of all these great technological advancements of the $21^{\text {st }}$ century, the core curriculum in engineering education, still follows the footsteps of teaching of a century ago, is delivered through lectures, recitations and laboratory classes if applicable. In many ways, this classical teaching does not meet the expectation of millennial generation [7]. Goodhew [8] stated that active methods of learning are more effective in deep learning than passive methods such as seminars, and lectures. Nevertheless, class delivery through lectures is most of the time only feasible path due to the economic and physical restraints. But still, minor reforms and modernization in curricula has been acknowledged in many institutions, tools such as e-learning, online/virtual laboratories and open online courses are implemented well in the system to improve student engagement.

Instead, art and design education embraces a wide range of teaching approaches, which includes studio practice, lectures, seminars, one to one tutorials, group critiques, and gallery-based learning. 
Considering the fact that, learning is highly relational, and affected by the development and quality of relationships between students and lecturers but also the relationships between students themselves [9]. Students are likely to derive most benefit from critiques and feedbacks on their own work in art and design education. Hence, the educators become much more aware of student's engagement, and examine the factors that are in play in driving such student retention, and provide pastoral care. The very fact that, this learning only takes place at an individual level, and it is not enough to create a collaborative learning environment. As stated by Senior and Howard, the students who learn collaboratively achieve higher grades than students working independently, and use group work to develop and enforce their emerging professional identity [10]. Both in engineering and art \& design education, they provide for each learner different learning paths to optimize their own learning curves.

If we start asking the question "how could we create a common language which helps bridge the gap between design and engineering?". We are seeking solutions to foster communication in different disciplines, and exploring new learning tools both in engineering and design education. This paper attempts finding a common ground for engineers and designers by presenting my personal views regarding teaching experience in engineering and art schools and how I envisage the engineers and designers in future working in smart textiles ought to be taught like.

\section{METHODOLOGY}

The methodology section began with identifying missing elements and challenges for a successful collaborative working environment. Then, the importance of technology, and virtual learning environment tools was highlighted in the context of smart textiles. The strategies that may have a significant benefit in teaching diverse learners was explored.

In the emerging field of smart textiles, both engineers and designers need a solid understanding of what is feasible to make. For a sustainable collaboration, designers should know how each component is constructed and functioned from an engineer's perspective. While engineers should consult with designers and trust their vision and approach from a user's perspective. In other words, textile designers must be equipped with knowledge of fundamental textile production methods and materials, which includes properties of natural and man-made textile materials, main principles of textile processes such as spinning, weaving, finishing, and knitting. On the other hand, while the curriculum in art and design education encourages students to experiment with unconventional materials and processes, it does not deal with the study of the basic laws of nature and their manifestation in their design. So far in classical engineering education, tactile interaction between human and product and the importance of visually appealing finished products on the success are mostly disregarded. There are several strategies that can be used to increase awareness in this matter, modifying curriculum to inculcate understanding of cross-disciplinary approach is one of them. In many technical universities, students are taught fundamental design engineering classes representing ergonomics and design thinking. However, this knowledge is delivered through lectures, which has limited contribution in student engagement and weak knowledge transfer to practice. As educators, modifying our methods of teaching to use more active techniques could create drastic changes in knowledge transfer. For instance, in a field such as smart textiles where craftsmanship and technology should work in harmony with each, educators must reshape their teaching strategies for innovative and tangible materials and include more student-led experiences focused on the physicality. In undergraduate level, to involve both engineering students and textile designers in group or team work, helps students to address the role of each disciplines and to shape their identity as designers and engineers.

The students in graduate level have different motivation than the undergraduate students as the time and effort students devote to activities due to work and family commitments and having refined intellectual curiosity. Thus, the educators should re-structure their teaching strategies with focus on projects and real-world issues. Meanwhile, virtual learning and teaching tools are more accessible than ever before. In the context of smart textiles, designers who want to expand their knowledge in fundamental science and coding, can attend online tutorials and virtual libraries. But as educators, we have an important role in facilitating learning, and demonstrate them how these virtual learning tools such as online tutorials, open courses, audio/video lectures may have a significant benefit in their practice, and be attached on their learning scheme. Not only learners but also tutors/lecturers can embed similar tools to interactive Top Hat ${ }^{\circledR}$ class management module which will help them advance in their teaching careers while increasing student participation by also providing appropriate assessment and feedback. In other words, when the educators have a diverse audience, it would be wasted effort 
to follow classical passive teaching methods, so the distinct learning needs, interests, or different academic backgrounds of learners should be addressed individually. For instance, when a textile designer works with materials using the merits of nanotechnology where the design itself starts at nanoscale due to possibilities of atom manipulation. From a personal perspective, to demonstrate the scale of capabilities and to provide insightful feedback, it is needed to put efforts to create personalized teaching strategies while focusing on identifying each design's practical constraints and designers intellectual profundity. Results section reflects observations during my personal pedagogical journey to engage students with different backgrounds and to provide achievable feedback.

\section{RESULTS}

This section gives self-critical view of my own blend of teaching that I developed with the help of undergraduate and graduate students both from design and engineering disciplines. As academics and researchers in higher education institutions, frequently we have been given the task of lecturing to students at different levels. In the early years of my profession, first I observed that there was a considerable shift in student retention based on the level of undergraduate or post-graduate studies. Huang proposed an adult learner retention model that pointed out successful experience regarding psychological factors, as depicted in Figure 1 [11]. In post-graduate studies, adult learners do not retain in class when they feel a lack of progress in their academic track. Thus, as in most of engineering education, if educators have to follow curriculum conducting through series of lectures, it might be difficult to maintain student engagement. While in art and design, tutors still have ability to shape and personalize their teaching methods based on adult learner's practice and provide appropriate feedback. In this paradigm, this personalized way of teaching allows us to focus on the characteristics and qualities of individual students.

As in all other multi-disciplinary fields, smart textiles is the subject for academics working across a wide range of fields from design, fashion, textiles, to electronics, computing, material science. Hence, creating a common language between tutors and students, and peers takes time but it is essential for an efficient and functional work environment. Sometimes simple concepts such as "Colour" might be perceived differently. For instance, for physicists "Colour" is light, and when it is refracted through a glass prism, it split into the spectrum of various colours ranging from red to blue, which also reflects how it becomes open to the manipulation of engineers and scientists. For designers, intertwined with science, "colour" is tricky but quite expressive and incredibly subjective. As Vincent Van Gogh expressed "Colour in a painting is like enthusiasm in life" while artists explore its visual effects in different mediums. Thus, I believe that even the perception of very well-known subjects might differ, since it is evolving and shaping throughout time.

Adult learning process

and retention model

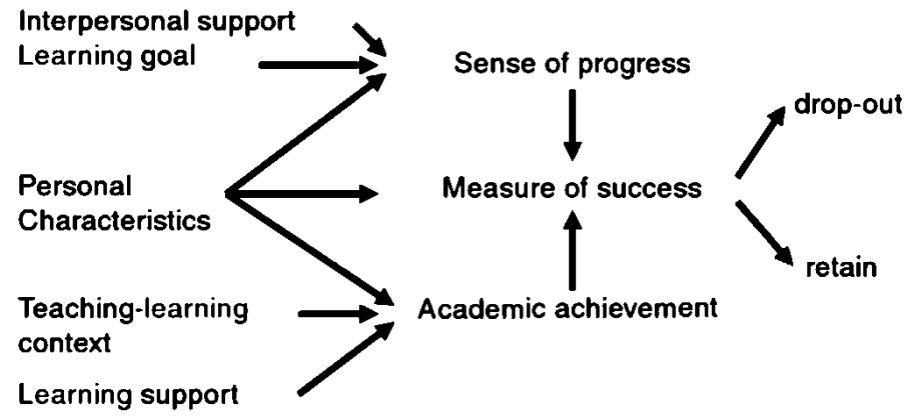

Figure 1. Adult Learning Retention Model proposed by Huang [10] 


\section{CONCLUSIONS}

Based on my experience, the points that might help to build successful communication in smart textiles which is a multi-disciplinary field using the merits of nanotechnology, electronics and textile design.

- Educators must embrace virtual learning tools, animations and online tutorials in technological fields to reach students with different backgrounds, especially to the ones who never studied quantum mechanics, chemistry and materials science before. Visualisation is effective in addressing complex subjects.

- Active methods of learning including project based and hands-on learning is more effective than passive lectures, especially in post-graduate level, which advances also educators' ability to impart knowledge.

- The tangible nature of resources, particularly in smart textiles, and also their effect on learning should not be avoided. It brings a different perspective of ergonomics to textiles than any other discipline, and it is evolved from conceptual design through practice.

- As Nobel laurate Albert Einstein stated "Imagination is more important than knowledge. For knowledge is limited, whereas imagination embraces the entire world, stimulating progress, giving birth to evolution. It is, strictly speaking, a real factor in scientific research." [12]. Also in teaching, there must always be room for imagination and creativity where learners can also contribute to bilateral knowledge transfer, that should be considered in designing curriculum both in undergraduate and graduate studies.

\section{ACKNOWLEDGEMENTS}

The authors thanks Royal College of Art for EO/RC/138 numbered travel support to attend ICERI 2018. This project has received funding from the European Union's Horizon 2020 research and innovation programme under grant agreement No 796640 .

\section{REFERENCES}

[1] E. Pei, "Building a common language of design representations for industrial designers \& engineering designers" IN: Evans, M.A. (ed.). Case studies in the use of design practice by PhD researchers. [Online]. 2009. Retrieved from http://www.lboro.ac.uk/microsites/lds/dprgcasestudies/

[2] S. Persson, C. Wickman, "Effects of industrial design and engineering design interplay: An empirical study on tolerance management in the automotive industry" Design 2004: Proceedings of the 8th International Design Conference, Vols. 1-3 pp. 1151-1160, 2004.

[3] K.M. Kim, K. Lee, "Collaborative product design processes of industrial design and engineering design in consumer product companies", Design Studies, Volume 46, , pp 226-260, September 2016

[4] W.E. Eder, "Engineering design vs. artistic design: some educational consequences", US-China Education Review A, 3, pp. 259-280, 2013

[5] ABET Engineering definition, Retrieved from https://en.wikipedia.org/wiki/Engineering\#cite_note-ECPD_Definition_on_Britannica-4

[6] P. Kapranos, "Teaching and Learning in Engineering Education - Are we moving with the times?", Procedia - Social and Behavioral Sciences 102, pp 3 - 10, 2013.

[7] G.K. Svedberg, "Critical Self-Reflections on The Classical Teaching Culture in Engineering", Proceedings of the $7^{\text {th }}$ International CDIO Conference, [Online]. 2009. Retrieved from https://muep.mau.se/bitstream/handle/2043/12550/7th_CDIO_Conference_paper_63.pdf?seque nce $=2$ 
[8] P. Goodhew, "Teaching Engineering: Can we do it better?" Proceedings of 4th International Symposium for Engineering Education, University of Sheffield, 19th-20th July, 2012, UK, Ed. P Kapranos \& D Brabazon, 201, .pp 1-7, 2012.

[9] K. J. Gergen, Relational Being: Beyond Self and Community. New York, NY: Oxford University Press, 2011.

[10] C. Senior and C. Howard, "The state of the art in student engagement". Front. Psychol. 6, 355, 2015.

[11] T.J Huang, "A Research on Learner Retention and Learning Support", US-China Education Review, Volume 2, No.1, 2005.

[12] A. Einstein, "Cosmic Religion: With Other Opinions and Aphorisms", Covici Friede Publisher, New York, p.97, 1931. 